\title{
Satellite Remote Sensing of Wheat Infected by Wheat streak mosaic virus
}

\author{
M. Mirik, Texas AgriLife Research, Vernon 76385; D. C. Jones, J. A. Price, and F. Workneh, Texas AgriLife Research, Bushland
} 79012; R. J. Ansley, Texas AgriLife Research, Vernon 76385; and C. M. Rush, Texas AgriLife Research, Bushland 79012

\begin{abstract}
Mirik, M., Jones, D. C., Price, J. A., Workneh, F., Ansley, R. J., and Rush, C. M. 2011. Satellite remote sensing of wheat infected by Wheat streak mosaic virus. Plant Dis. 95:4-12.

The prevalence of wheat streak mosaic, caused by Wheat streak mosaic virus, was assessed using Landsat 5 Thematic Mapper (TM) images in two counties of the Texas Panhandle during the 2005-2006 and 20072008 crop years. In both crop years, wheat streak mosaic was widely distributed in the counties studied. Healthy and diseased wheat were separated on the images using the maximum likelihood classifier. The overall classification accuracies were between 89.47 and $99.07 \%$ for disease detection when compared to "ground truth" field observations. Omission errors (i.e., pixels incorrectly excluded from a particular class and assigned to other classes) varied between 0 and $12.50 \%$. Commission errors (i.e., pixels incorrectly assigned to a particular

There were substantial differences between planted wheat acreage reported by the United States Department of Agriculture-National Agricultural Statistics Service (USDA-NASS) and that detected by image analyses. However, harvested wheat acreage reported by USDANASS and that detected by image classifications were closely matched. These results indicate that the TM image can be used to accurately detect and quantify incidence of wheat streak mosaic over large areas. This method appears to be one of the best currently available for identification and mapping disease incidence over large and remote areas by offering a repeatable, inexpensive, and synoptic strategy during the course of a growing season.
\end{abstract} class that actually belong to other classes) ranged from 0 to $23.81 \%$.
Wheat streak mosaic (WSM), caused by Wheat streak mosaic virus (WSMV), is a viral disease that affects wheat (Triticum aestivum $\mathrm{L}$.), barley (Hordeum vulgare $\mathrm{L}$.), oat (Avena sativa $\mathrm{L}$.), maize (Zea mays L.), millet (Panicum setaria), and numerous other grasses over large geographical areas around the world $(7,20,77)$. This virus is vectored by the wheat curl mite (Aceria tosichella Keifer) (74), which has several grass species hosts besides wheat $(14,30)$. Initially, disease symptoms on infected wheat plants are characterized by light chlorotic streaking and mosaic of young leaves. As the disease progresses, infected plants exhibit stunting, extreme chlorosis, and mosaic, and in severe cases chlorotic leaves become necrotic and the plant eventually dies $(60,70,83)$. This response to infection is especially common when wheat plants are doubly infected by WSMV and other mite-vectored viruses, such as Triticum mosaic virus or Wheat mosaic virus $(7,59)$. Symptom severity also depends on wheat cultivar, time of infection, temperature, and other environmental conditions that affect vector populations and plant growth (15). Since its first discovery in 1922 in Nebraska, WSMV has periodically caused severe epidemics across most of the Great Plains of the United States (77). In this region, much of the wheat is grown as a dual purpose crop, for both winter forage and grain production. Studies have demonstrated that WSM reduces yield and quality of both forage and grain in wheat production systems $(33,38)$. WSM has been estimated to decrease annual wheat yields by approximately $5 \%$ per year, but local disease epidemics can be highly destructive and result in total crop loss $(20,73)$

In the Texas Panhandle, and throughout the Southwestern Great Plains, much of the winter wheat crop is irrigated with ground water from the Ogallala aquifer. Grain yields from irrigated wheat

Corresponding author: M. Mirik, E-mail: mmirik@ag.tamu.edu

Accepted for publication 31 August 2010.

doi:10.1094/PDIS-04-10-0256

(C) 2011 The American Phytopathological Society are often three to four times greater than yields from dryland production, but reduced water levels in much of the aquifer threaten irrigated production. For this reason, research has focused on factors that impact irrigation and crop water use efficiency (WUE). A majority of this effort has addressed the mechanics of water delivery systems, or agronomic and soil physical characteristics that affect WUE, but recent studies have demonstrated the negative impact of WSM on root development and WUE $(60,83)$. Wheat plants severely infected by WSMV have significantly smaller root systems than healthy plants and are unable to take advantage of available soil moisture, regardless of the source. For this reason, application of irrigation to severely infected wheat constitutes a waste of time, energy, and natural resources, and the economic impact of WSM is significantly greater in irrigated than in dryland production systems (80). With the advent of site-specific irrigation technology, avoiding irrigation of severely infected wheat could result in significant savings, but to achieve this goal, improved methods of disease detection are needed.

To improve disease management and crop production, it is essential to have adequate methods for monitoring disease epidemics at various scales and multiple times (44). Remote sensing has become an essential tool for monitoring and quantifying crop stress due to biotic and abiotic factors $(44,65)$. Results from greenhouse and field studies have shown that it is possible to observe and quantify changes in crop health using remote sensing over the course of a growing season (65). The presence of a disease or insect feeding leads to reductions in green leaf area and chemical and pigment concentrations, and alteration of cell structure, water and nutrient uptake, and gas exchange. These alterations in affected tissue reflect the overall changes in photosynthesis, transpiration, metabolism, and temperature $(56,81)$, which is known to modify canopy reflectance characteristics $(62,81)$. Measuring the light reflected by the canopy area with a remote sensing device, therefore, potentially provides a quick, nondestructive, and inexpensive method for identifying and quantifying infected areas (45). Optical properties of mature and healthy green leaves, plants, or canopies are characterized by high absorption in the blue $(400-500 \mathrm{~nm})$ and the red $(600-700 \mathrm{~nm})$, but high reflectance in the green $(500-600$ 
$\mathrm{nm}$ ), and very high reflectance and transmittance in the near infrared (NIR: $700-1,500 \mathrm{~nm}$ ) range $(22,31,81)$. Spectral responses of vegetation in the visible $(400-700 \mathrm{~nm})$ region are primarily governed by the abundance of chlorophylls, carotenoids, and anthocyanins $(6,21,31,56)$. The optical properties of vegetation in the NIR are due to the discontinuities between cell walls and intercellular air spaces in internal leaf structure $(31,56,81)$. Reflectance in the shortwave infrared (SWIR: 1,200-2,400 nm) is affected due to absorptions by water, proteins, and other carbon constituents in the vegetation $(32,68)$. Reduction in green leaf area due to growth limiting factors (pathogens, insect feeding, nutrient deficiencies), leaf senescence, and defoliation causes high reflectance in the visible spectrum due to chlorophyll degradation, low reflectance in NIR due to reduced green leaf area and senescence, and high reflectance in SWIR due to modified tissue chemistry $(27,32,54,81)$.

Reflectance differences in the visible and NIR regions have led to the development of spectral vegetation indices. Spectral vegetation indices are mathematical terms of reflectance values at different parts of the spectrum, aimed to increase the extraction of optimal spectral information and intended to normalize the measurements made in varied environmental conditions $(5,6$, $43,46,85,86)$. Varied environmental conditions may include differences in plant species, solar angle, shadowing, illumination, canopy coverage, soil background, atmospheric condition, and viewing geometry of the device over space and time $(48,66,85,86)$. In general, some of these indices were designed to measure leaf chemistry such as nitrogen, lignin, neutral detergent fiber, and phosphorus $(47,71)$, whereas others were developed to evaluate the variations in vegetative attributes such as green leaf area (35), wet and dry biomass $(69,79)$, micronutrient deficiency (1), water content and stress $(10,18,68)$, chlorophyll, carotenoid, and anthocyanin contents (24-26), and disease (2). Perhaps the best known and most popular are the Simple Ratio (SR) proposed by Jordan (35) and the Normalized Difference Vegetation Index (NDVI) developed by Rouse et al. (69) using broadband multispectral remotely sensed data. Researchers have argued that remote sensing offers a better means to detect and quantify the impact of plant disease pathogens in vegetation compared to visual techniques because a vegetative unit can be repeatedly, objectively, and nondestructively examined in a fast, robust, accurate, and inexpensive way $(28,29$, $52,53,57,58,75,76)$.

Riedell and Blackmer (66) conducted a greenhouse study using a portable spectrometer to identify wavebands sensitive to greenbug (Schizaphis graminum Rondani) and Russian wheat aphid (Diuraphis noxia Mordvilko) stress to wheat and found that leaf reflectance in 625-635 nm and 680-695 nm bandwidths, as well as the Normalized Total Pigments to Chlorophyll $a$ Ratio Index (NPCI) were good indicators of chlorophyll loss and leaf senescence caused by aphid feeding damage. Yang et al. (85) used a hand-held radiometer in greenhouse experiments to characterize greenbug stress in wheat and found that a waveband centered at $694 \mathrm{~nm}$ and spectral vegetation indices derived from wavelengths centered at 800 and $694 \mathrm{~nm}$ were identified as most sensitive to greenbug-damaged wheat. Mirik et al. $(43,44)$ reported significant differences in reflection patterns of wheat canopies with and without greenbug and Russian wheat aphid feedings using hyperspectral field data, respectively. Significant correlations between spectral reflectance data and symptoms of net blotch (Pyrenophora teres) in barley, glume blotch (Stagonospora nodorum) in winter wheat, and both diseases in spring wheat were reported by Nilsson (50). Nilsson and Johnsson (51) found significant correlations between the radiometric assessment of barley stripe disease (Pyrenophora graminea) and grain yield. Lelong et al. (37) identified differences in well-developed and water stressed wheat canopies by analyzing an image. Huang et al. (32) tested the photochemical reflectance index (PRI) derived from hyperspectral imagery to characterize yellow rust (Puccinia striiformis) in wheat and concluded that PRI has the potential for quantifying yellow rust levels in wheat fields. Franke and Menz (19) used multispectral satellite image for quantifying wheat infected by powdery mildew
(Blumeria graminis) and leaf rust (Puccinia recondita) at different infective stages in an experimental field. The researchers demonstrated that multispectral images are generally suitable to detect infield heterogeneities in wheat vigor, particularly for later stages of fungal infections, but only moderately appropriate for distinguishing early infection levels in wheat. In addition to studies on insect feeding and foliar diseases in wheat, remote sensing has been effectively used to detect rhizomania in sugar beet (Beta vulgaris) (76), European corn borer (Ostrinia nubilalis) in corn (Zea mays) (8), Verticillium wilt in cotton (Gossypium hirsutum) (11), arthropod damage in cotton (63), Ustilaginoidea virens in rice (Oryza sativa) panicles $(39,40)$, foliar diseases in alfalfa (Medicago sativa) $(27,28,52)$, soybean (Glycine max) (54), peanut (Arachis hypogaea) (53), and pyrethrum (Tanacetum cinerariifolium) $(57,58)$, and sunn pest (Eurygaster integriceps) (23), greenbug $(17,46)$, Russian wheat aphid (16), and stem sawfly (Cephus cinctus) (49) in wheat.

Although spectral detection and quantification have been successful in plant science, and have been used at local (field) levels for assessing WSM $(34,82,83)$, use of satellite remote sensing for detection and quantification of WSM has never been attempted. We hypothesize that Landsat 5 Thematic Mapper (TM) can provide a sufficient and inexpensive data base for remote sensing of WSM over large regions. In addition, Landsat offers the advantage of continuously collected data and availability of immediate or archived data sets. However, it may have limitations for temporal monitoring due to cloud cover. Processing time required by the image provider for high-resolution satellite data that are usually not archived and continuously collected (e.g., QuickBird, IKONOS) may complicate timely acquisition of data along with cloud cover for monitoring real time occurrence of WSM in commercial wheat fields. Therefore, continuously collected data and availability of Landsat real time and past images are appealing as a research method for WSM. The main objective of the present study was to assess the use of satellite imagery for detecting and quantifying the county-wide occurrence of WSM in commercial wheat fields in the Texas Panhandle using Landsat 5 TM data. Our secondary objective was to investigate disease occurrence in dryland and irrigated wheat fields using the same methodology. Early detection of WSM symptom expression when only a few chlorotic streaks were present on leaves was not considered for identification of diseased wheat in this study because previous studies using highresolution imagery and ground reflectance data found that it is difficult to detect initial stages of symptoms using remote sensing $(19,28,29,52,61,67,87)$.

\section{Materials and Methods}

During the 2005-2006 and 2007-2008 wheat growing seasons (September to May), a series of cloud free Landsat 5 TM images covering the northwestern Texas Panhandle with path 31 and row 36 and scene center latitude $34.613^{\circ}$ and longitude $-102.896^{\circ}$ were obtained every 16 days, which is the revisiting time period of Landsat for the same area. Images were provided by the United State Geological Service (USGS) via the Center for Space Research, University of Texas at Austin, with geometric and radiometric corrections. The images, each covering about $33,659.5 \mathrm{~km}^{2}$ of the same area (roughly $181 \times 186 \mathrm{~km}$ ), were projected to the Universal Transverse Mercator, North American Datum 1983, Zone 13 North. Images were subset for two adjacent counties, Castro and Deaf Smith, in 2005-2006 and 2007-2008, respectively (Fig. 1) using Environment for Visualizing Images software package (ENVI: ITT Visual Information Solution, Boulder, CO). These two counties were chosen because of easy field verification (ground-truthing), high wheat production, widespread occurrence of WSM, and similarities in stage of disease progression in these years. Images used for this study were from 28 January and 18 April 2006, and 19 February, 22 March, 9 April, and 9 May 2008. Images prior to January in each wheat growing season were not suitable due to low growth of wheat from drought or livestock grazing. 


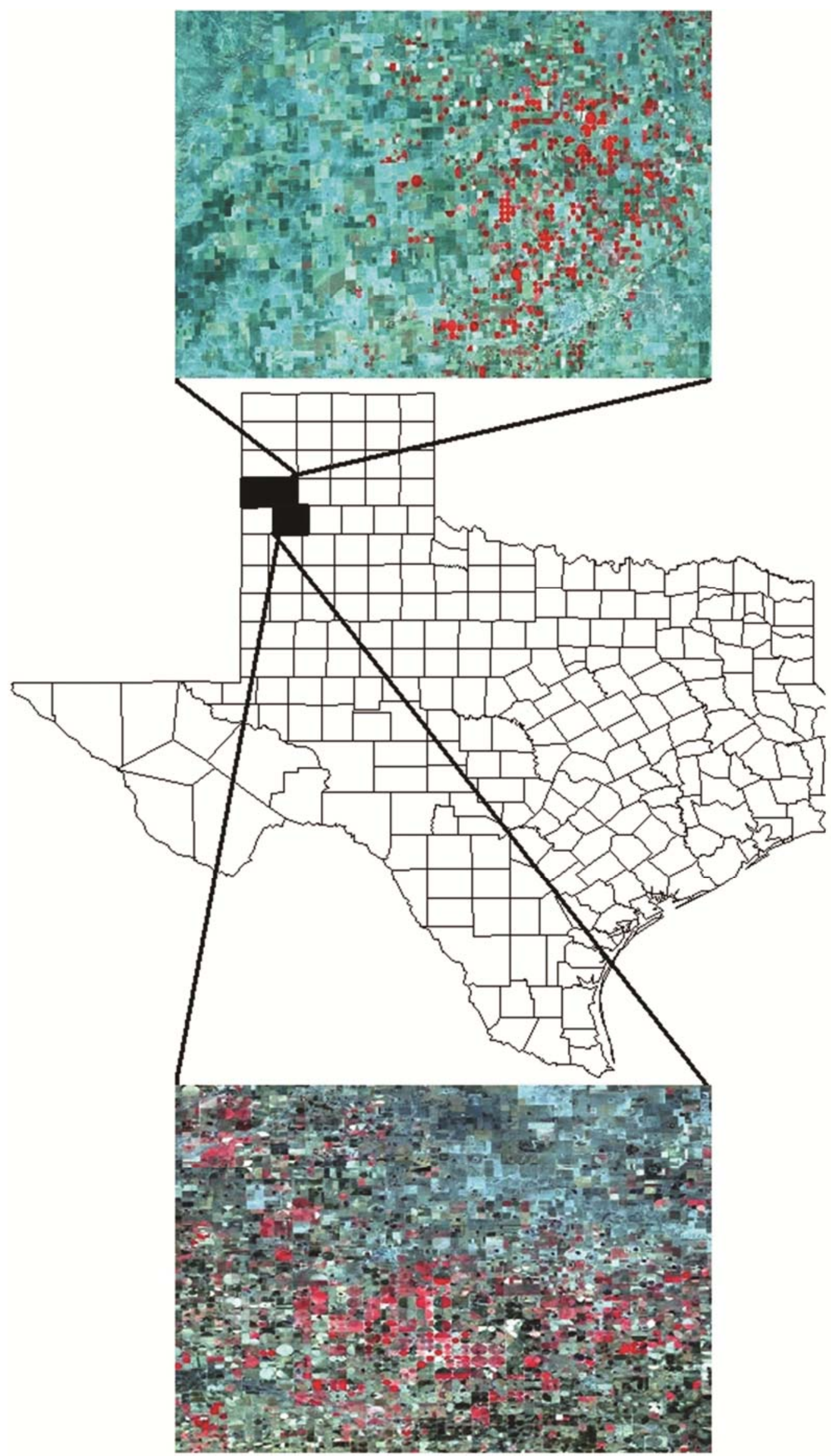

Fig. 1. Landsat 5 Thematic Mapper (TM) color infrared images of wheat fields in Texas with red dots showing wheat fields for Deaf Smith (top) and Castro (bottom) counties. 
Prior to classification of diseased and healthy wheat fields, all nonwheat areas (e.g., native grassland, exposed soil, water, roads, fallow fields, etc.) were masked out on the images using normalized difference vegetation index (NDVI $=$ Band $4-$ Band $3 /$ Band4 + Band3, Table 1). The earliest image in each year (28 January 2006; 19 February 2008) was used for this purpose because native grasslands were dormant (light brown color) and yielded a different spectral property than diseased wheat fields, which were in the early stages of disease and remained much greener than dormant native grassland. An NDVI value of $<0.1000$ was sufficient to mask out nonwheat areas in both years, and a "nonwheat" image using this NDVI value was created using ENVI for these two dates. These images were then applied to the other dates in 2006 and 2008, respectively (Fig. 2).

After the masking process, wheat-only areas were converted to false color infrared images for each date, and WSM was classified using the maximum likelihood classifier (MLC), which is a type of supervised classification technique in ENVI. Supervised classification is a procedure for identifying spectrally similar areas on an image in which the user defines known cover types as "training samples", and then the MLC extrapolates those spectral characteristics to other areas for class identifications $(9,41,64,72)$. The types of classification techniques are also called pixel-based, parametric (statistical), spectral, and hard classification $(36,41)$. The MLC is based on the assumption that members of each class are normally distributed in an image. Implementation of the MLC involves the estimation of class mean vectors and covariance matrices using training samples of each particular class $(55,64)$. Training samples consist of groups of individual pixels, polygons, or individual spectra $(55,64)$. If the assumption of a normal distribution for each class is correct, then the classification has a minimum overall probability of error and the MLC is the optimum choice (78). Therefore, the MLC has been widely used to classify images by the remote sensing community (72). Several reviews of various techniques used in remote sensing data analysis and classification have been previously published (41).

For the classification in our study, regions of interest with previously identified diseased and healthy wheat were manually selected in satellite images as the training samples to represent respective diseased and healthy classes. For the accuracy assessment, 256, 324, 285, and 147 ground verification (ground-truthing) points were randomly generated using ArcMap (ESRI, Inc., Redlands, CA) for 28 January 2006, 18 April 2006, 19 February 2008, and 9 May 2008 images, respectively. Ground-truthing surveys were not conducted for 22 March and 9 April 2008 images. The training samples were not included in ground-truthing points. The ground-truthing points were exported to a field computer equipped with the Farm Works software package (CTN Data Service, Hamilton, IN) and a GPS receiver and were navigated on the ground for field verification. Error matrices for each classification map were generated by comparing the classified classes with the ground classes at these points. Error matrices to evaluate the classification accuracy were calculated and included overall accuracy (accuracy of the entire image without indicating the accuracy of individual class), commission error (pixels incorrectly assigned to a particular

Table 1. Specifications of Landsat 5 Thematic Mapper (TM) image used to detect healthy and diseased wheat caused by Wheat streak mosaic virus across Castro and Deaf Smith counties in Texas in 2006 and 2008 crop years

\begin{tabular}{lcc}
\hline & \multicolumn{2}{c}{ Resolution } \\
\cline { 2 - 3 } Band & Spectral $(\mathbf{n m})$ & Spatial $(\mathbf{m})$ \\
\hline 1-Blue-green & $450-520$ & 30 \\
2-Green & $520-600$ & 30 \\
3-Red & $630-690$ & 30 \\
4-Near infrared & $760-900$ & 30 \\
5-Middle infrared & $1,550-1,750$ & 30 \\
6-Thermal infrared & $10,400-12,500$ & 120 \\
7-Middle infrared & $2,080-2,350$ & 30 \\
\hline
\end{tabular}

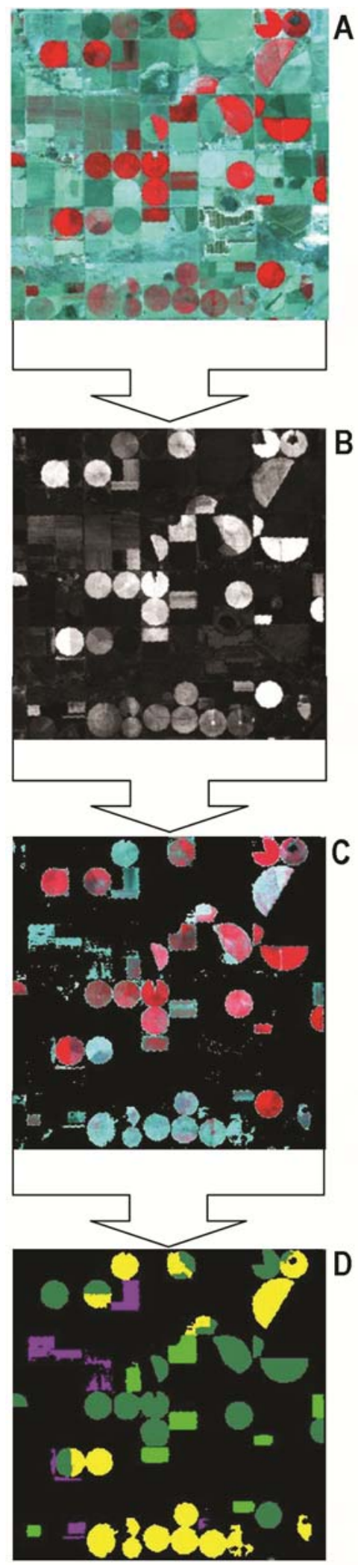

Fig. 2. Steps of image processing for detecting and mapping wheat infected by Wheat streak mosaic virus. A, False color composite Landsat 5 Thematic Mapper (TM) image. B, Normalized Difference Vegetation Index (NDVI) image. C, False color composite image masked using NDVI image. NDVI images were created from early-season images and applied to images obtained thereafter for masking out nonwheat surface components in 2006 and 2008 growing seasons. D, Classified image using maximum likelihood classifier within masked false color composite image (C). Irrigated healthy wheat, dark green; irrigated diseased wheat, yellow; dryland healthy wheat, green; dryland diseased wheat, purple. 
class that actually belong to other classes), omission error (pixels incorrectly excluded from a class and assigned to other classes), and kappa statistics $(12,13)$. Kappa is a discrete multivariate technique normally used in accuracy assessment, which is another measure of accuracy $(12,13)$. It indicates how well the classification result agrees with the actual data with values ranging between 0 and $1(3,12,13)$. When the kappa value approaches zero, there is a poor agreement, and when it approaches 1, there is a strong agreement between classified and actual categories (13). The overall accuracy is the sum of the number of pixels classified correctly and divided by the total number of pixels, which is meaningful for a whole classification map $(12,13,84)$. The omission error was calculated by the total number of correctly classified pixels in a category divided by the total number of pixels of that category as derived from the actual data (the column total). On the other hand, the commission error was calculated by the number of correctly classified pixels in each category divided by the total number of pixels that were classified in that category (the row total) (3). Both omission and commission errors are meaningful for individual classes such as irrigated diseased or dryland healthy wheat categories.

In order to validate image classification accuracy, and to verify that observed disease symptoms were caused by WSMV, ground surveys were conducted during both years of this study. Samples from fields of interest were tested for WSMV prior to the image classification. Wheat samples were collected, placed into plastic bags, and transported to the Great Plains Diagnostic Network, plant pathology laboratory at the Texas AgriLife Research and Extension Center in Amarillo for processing. Each sample consisted of multiple leaves or tillers, and individual samples were collected arbitrarily from three to four locations within each field for each classified category. Infection by WSMV was verified by double antibody sandwich enzyme-linked immunosorbent assay (DAS-ELISA) using standard Agdia protocol and reagents (Elkhart, IN) with minor modifications (59). Polystyrene plates (Fisher Scientific, San Francisco, CA) were used to reduce buffer and antibody serum from $100 \mu \mathrm{l}$ to $50 \mu \mathrm{l}$, and WSMV antiserum was used at a 1:200 ( $\mathrm{vol} / \mathrm{vol})$ dilution. Tissue was ground at a ratio of $1 \mathrm{~g}: 10$ $\mathrm{ml}$ extraction buffer. Individual sample wells were evaluated by absorbance at $405 \mathrm{~nm}$ using an Emax precision microplate reader (Molecular Devices Corp., Union City, CA). Tissues from noninoculated wheat grown in a greenhouse served as controls. Absorbance values greater than 3 times the healthy controls were considered positive.

Based on results of diagnostic tests for WSMV and incidence of disease symptoms, fields were designated as diseased or healthy.

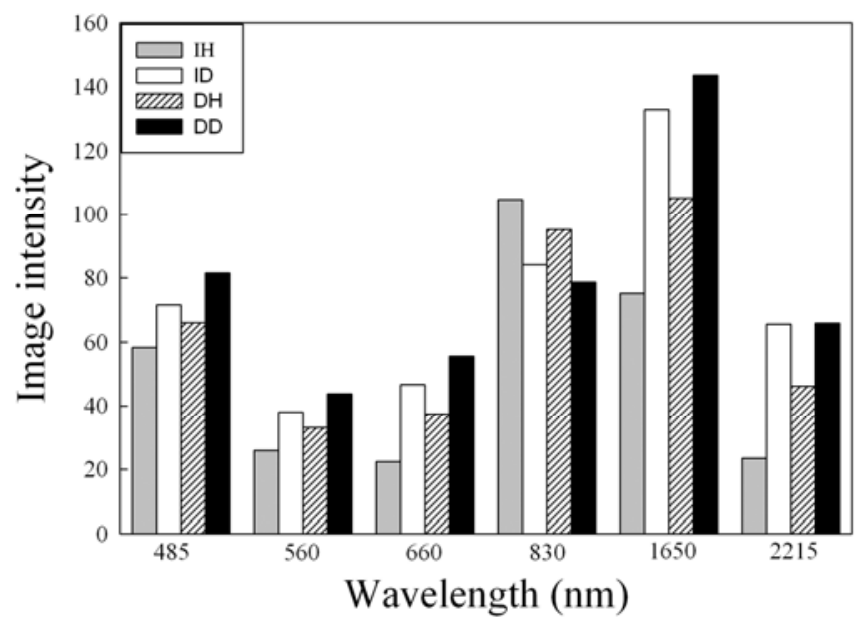

Fig. 3. Spectral response of irrigated and dryland wheat canopies with and without wheat streak mosaic (WSM) extracted from training samples for each category and used to supervise maximum likelihood classification for Landsat 5 Thematic Mapper (TM) bands $(485-2,215 \mathrm{~nm})$ on 9 May 2008. IH: irrigated healthy, ID: irrigated diseased, DH: dryland healthy, DD: dryland diseased.
Fields or areas within fields identified as diseased were those in which at least $40 \%$ of the plants were infected by WSMV and exhibited severe disease symptoms of stunting, chlorosis, leaf curling, and mosaic. Fields or areas within fields classified as healthy typically had less than $10 \%$ of the plants with severe symptoms of WSM. Some fields classified as healthy had $>10 \%$ of the plants infected by WSMV but symptoms were not severe: usually a result of late-season infection. Such plants exhibited slight streaking but were not stunted and still predominately green. Studies have shown that late-season infection has minimal effect on plant development and yield (author's personal observations; 33). Areas of interest were manually digitized on images of healthy and diseased wheat fields and used to supervise the MLC for classifications.

To address objective 2, we examined the spectral characteristics of irrigated and dryland healthy and diseased wheat from training samples of each category across six bands of TM imagery. A paired $t$ test procedure for comparing the image intensity values (image digital numbers) from healthy and diseased wheat was performed using SigmaStat (Systat Software Inc., Rochester, $\mathrm{MN}$ ), and statistical significance of paired $t$ test was evaluated at $\alpha=0.01$.

\section{Results}

Paired $t$ test comparisons from training samples used for classification yielded significant differences $(\alpha=0.01)$ in all areas of the electromagnetic spectrum except for irrigated versus dryland diseased wheat $(P=0.55)$ at $2,215 \mathrm{~nm}$ band center (Fig. 3). Both dryland and irrigated healthy wheat canopies had lower image intensity (image digital number) in the visible (485, 560, and 660 $\mathrm{nm})$ and SWIR band centers (1,650 and 2,215 $\mathrm{nm})$, and higher intensity in the NIR band center $(830 \mathrm{~nm})$ than did diseased wheat canopies.

Classification of the Landsat TM image from 28 January 2006 for Castro County identified 56,168 ha of wheat planted (dryland + irrigated) in a 233,371 -ha area and that 17,893 ha were classified as diseased. Overall, $96.09 \%$ of the known ground-truth points were classified correctly with a kappa value of 0.92 (Table 2). Omission errors were $2.68 \%$ for diseased wheat and $4.86 \%$ for healthy wheat, whereas commission errors were $6.03 \%$ for diseased wheat and $2.14 \%$ for healthy wheat. For this date, of the total 256 fields, 3 were misclassified as diseased wheat, while 7 diseased fields were misclassified as healthy.

Classification of the Landsat TM image from 18 April 2006 revealed 22,290 ha with 10,700 ha identified as diseased. There were 33,878 ha difference in total wheat land area between the imageries classified for January and April. The overall accuracy for the April image was $99.07 \%$ with a kappa value of 0.98 (Table 2). Omission errors were $1.80 \%$ for diseased wheat and $0.47 \%$ for healthy wheat, whereas the commission errors were $0.91 \%$ for diseased wheat and $0.93 \%$ for healthy wheat. For this date, of the total 324 fields visited, 2 fields were misclassified as diseased wheat, while 1 diseased field was misclassified as healthy.

In 19 February 2008, 33,153 ha of dryland and 31,036 ha of irrigated wheat, totaling 64,189 ha, were detected by TM image across a 362,824-ha scene for Deaf Smith County. Overall classification accuracy was $89.47 \%$ with a kappa value of 0.79 for diseased and healthy wheat (Table 2). Diseased and healthy wheat had 8.51 and $12.5 \%$ omission errors, whereas commission errors were 12.24 and $8.70 \%$, respectively. There were 12 diseased fields misclassified as healthy fields, while 18 healthy fields were wrongly classified as diseased wheat by the method performed.

Classification of the TM image acquired on 22 March 2008 estimated 51,452 ha of wheat, with 31,036 ha irrigated and 20,416 ha dryland. Of the wheat detected, 11,491 ha were classified as diseased (dryland + irrigated) (classification accuracy not shown). The 7 April 2008 image contained 32,131 ha of wheat. Of these, 17,408 ha were irrigated and 14,723 ha were dryland (classification accuracy not shown). However, on 9 May 2008, the area of wheat detected by the classification was 21,062 ha, with 8,325 ha healthy and 12,737 ha diseased. Diseased wheat $(12,737$ ha) consisted of 
8,197 ha irrigated and 4,540 ha dryland wheat, whereas there were 4,348 ha irrigated and 3,977 ha dryland healthy wheat. The overall classification accuracy was $92.52 \%$ with a kappa value of 0.89 for the 9 May image (Table 3). The omission error for irrigated healthy and diseased wheat and dryland healthy and diseased wheat ranged from 0 to $12.5 \%$ (Table 2). Dryland healthy wheat had the highest commission error $(23.81 \%)$, whereas $0 \%$ commission error was achieved for dryland diseased wheat (Table 3).

\section{Discussion}

A significant increase in image intensity values from the diseased-wheat canopies in the visible region provided clear evidence that WSM degraded the photosynthetic pigments in wheat canopies. Lower image intensity in the NIR region in diseased wheat indicated that the WSM altered leaf tissue and structure, reduced green leaf area and biomass, and increased lesion formation. The increased image intensity in the SWIR band centers at both 1,650 and 2,215 $\mathrm{nm}$ in diseased wheat indicated that water, protein, and other carbon constituents were modified by WSM, leading to less canopy light absorption. These results were consistent with past studies on WSM and other pathosystems as well as insect infestations $(2,4,23,34,42-44,87)$. Jones (34) found that wheat infected by WSM could be separated from healthy wheat areas where high nitrogen was applied using plot-level digital images, but diseased and healthy wheat were not separable in nitrogen-deficient plots. Jones (34) also observed that values of spectral indices for diseased wheat due to WSM were significantly lowered compared to healthy wheat. Spectral responses of field bean (Vicia faba) infected by Botrytis fabae (42), tomato infected with late blight (87), and wheat infected by yellow rust (4), sunn pest (23), greenbug (44), and Russian wheat aphid (43) were higher in the visible and lower in the NIR regions of the spectrum when compared to healthy plants. Apan et al. (2) found a somewhat contrasting result that sugarcane infected by orange rust had lower reflectance values in the green light band than healthy tissue but reported the same spectral patterns we found for the remaining regions. Our results indicate that healthy wheat areas can be identified and separated from diseased areas.

To test the ability of multispectral TM data to identify countywide occurrence of WSM disease in wheat in the 2005-2006 and 2007-2008 crop years, the MLC was employed for image classification containing only wheat canopies. Wheat canopies were correctly separated from other surface components by masking the NDVI values that did not belong to a wheat crop. This is a relatively straightforward method for detection of winter wheat because wheat was the only green vegetation in late fall and winter in the study region. Later in spring when temperatures increased, some other cool-season grass species germinated or greened up. These areas may be confused with wheat because their NDVI values exceed 0.1000 . Typically these areas were limited to ditch banks, roadsides, playa lakes, and waste areas, and were too small to be detected on the Landsat image. The methods employed in this study could easily differentiate other crops that would be green such as alfalfa, winter peas, etc., from wheat, but would not be able to easily separate other small grains such as oats, rye, or triticale. However, none of these other crops were detected during our ground-level survey of the counties we studied.

This study showed that image processing techniques were repeatable between years and sites. Results of the accuracy assessments for WSM presence and absence demonstrated overall accuracies between 89.47 and $99.07 \%$. This indicates that the method used in this study can be used for large-area wheat moni-

Table 2. Classification accuracies for healthy and diseased wheat caused by Wheat streak mosaic virus in Castro and Deaf Smith counties in Texas using Landsat 5 Thematic Mapper (TM) images acquired on 28 January and 18 April 2006 and 19 February 2008

\begin{tabular}{|c|c|c|c|c|c|}
\hline \multirow[b]{2}{*}{ Image date } & \multirow[b]{2}{*}{ Classified category } & \multicolumn{2}{|c|}{ Actual category } & \multirow[b]{2}{*}{ Row total } & \multirow[b]{2}{*}{ Commission error (\%) } \\
\hline & & Diseased & Healthy & & \\
\hline 28 January 2006 & $\begin{array}{l}\text { Diseased } \\
\text { Healthy } \\
\text { Column total } \\
\text { Omission error }(\%) \\
\text { Overall accuracy }(\%) \\
\text { Kappa }\end{array}$ & $\begin{array}{r}109 \\
3 \\
112 \\
2.68 \\
96.09 \\
0.92\end{array}$ & $\begin{array}{c}7 \\
137 \\
144 \\
4.86\end{array}$ & $\begin{array}{l}116 \\
140 \\
256\end{array}$ & $\begin{array}{l}6.03 \\
2.14\end{array}$ \\
\hline 18 April 2006 & $\begin{array}{l}\text { Diseased } \\
\text { Healthy } \\
\text { Column total } \\
\text { Omission error }(\%) \\
\text { Overall accuracy }(\%) \\
\text { Kappa }\end{array}$ & $\begin{array}{r}109 \\
2 \\
111 \\
1.80 \\
99.07 \\
0.98\end{array}$ & $\begin{array}{c}1 \\
212 \\
213 \\
0.47\end{array}$ & $\begin{array}{l}110 \\
214 \\
324\end{array}$ & $\begin{array}{l}0.91 \\
0.93\end{array}$ \\
\hline 19 February 2008 & $\begin{array}{l}\text { Diseased } \\
\text { Healthy } \\
\text { Column total } \\
\text { Omission error }(\%) \\
\text { Overall accuracy }(\%) \\
\text { Kappa }\end{array}$ & $\begin{array}{r}129 \\
12 \\
141 \\
8.51 \\
89.47 \\
0.79\end{array}$ & $\begin{array}{c}18 \\
126 \\
144 \\
12.5\end{array}$ & $\begin{array}{l}147 \\
138 \\
285\end{array}$ & $\begin{array}{r}12.24 \\
8.70\end{array}$ \\
\hline
\end{tabular}

Table 3. Classification accuracies for healthy and diseased wheat caused by Wheat streak mosaic virus in Deaf Smith County in Texas using Landsat 5 Thematic Mapper (TM) image acquired on 9 May 2008

\begin{tabular}{|c|c|c|c|c|c|c|}
\hline \multirow[b]{3}{*}{ Classified category } & \multicolumn{4}{|c|}{ Actual category } & \multirow[b]{3}{*}{ Row total } & \multirow[b]{3}{*}{ Commission error $(\%)$} \\
\hline & \multicolumn{2}{|c|}{ Irrigated } & \multicolumn{2}{|c|}{ Dryland } & & \\
\hline & Diseased & Healthy & Diseased & Healthy & & \\
\hline Irrigated diseased & 52 & 4 & 0 & 1 & 57 & 8.77 \\
\hline Irrigated healthy & 1 & 42 & 0 & 0 & 43 & 2.33 \\
\hline Dryland diseased & 0 & 0 & 26 & 0 & 26 & 0.00 \\
\hline Dryland healthy & 3 & 2 & 0 & 16 & 21 & 23.81 \\
\hline Column total & 56 & 48 & 26 & 17 & 147 & \\
\hline Omission error (\%) & 7.14 & 12.50 & 0.00 & 5.88 & & \\
\hline Overall accuracy (\%) & 92.52 & & & & & \\
\hline Kappa & 0.89 & & & & & \\
\hline
\end{tabular}


toring during the growing seasons. High values of overall accuracy as well as low commission and omission errors illustrate that healthy wheat and wheat exhibiting severe symptoms of WSM was detectable in both the 2006 and 2008 multispectral images. Franke and Menz (19) reported the overall accuracies of 65.9 and $88.6 \%$ for wheat severely infected by leaf rust and powdery mildew using an airborne hyperspectral HyMap image with a spatial resolution of $4 \mathrm{~m}$ and a QuickBird satellite image with a spatial resolution of $2.4 \mathrm{~m}$, respectively. The researchers concluded that high-resolution multispectral imagers were appropriate to distinguish in field heterogeneities in wheat vigor, in particular when the crop is severely diseased. Healthy and diseased wheat infected by yellow rust were discriminated with a success rate of $96 \%$ using spectral images collected with a spectrograph in the field (4). The authors pointed out that their results were encouraging for the development of a cost-effective optical device for recognizing disease in the field during the early spring. Apan et al. (2) distinguished areas where sugarcane was infected by orange rust from disease free areas using a Hyperion imagery with $30 \times 30 \mathrm{~m}$ spatial resolution and concluded that this imagery can be used to detect orange rust disease in sugarcane. Nutter et al. (54) used a Landsat 7 imagery that has the same spatial resolution in the visible and SWIR ranges as the images we used and found that image intensity had higher $r^{2}$ values for soybean cyst nematode, Heterodera glycines, population density, soybean oil, and protein concentrations, but had lower $r^{2}$ values for soybean yield compared to either aerial image intensity or ground-based percentage reflectance measurements.

Early stages of WSM symptom expression when only a few chlorotic streaks were present on leaves were not considered for identification of diseased wheat in this study because earlier studies found that remote sensing images are not suitable for detecting initial symptoms of infection $(19,28,29,52,87)$. For example, in a study of powdery mildew and leaf rust of winter wheat, multispectral remote sensing imageries were not sensitive enough to distinguish slight disease symptoms when only lower leaves were infected by powdery mildew, but were capable of detecting high infection rates of leaf rust that rapidly affected whole canopies late in the growing season (19). A similar result was obtained by Zhang et al. (87) for late blight, caused by Phytophthora infestans, in field tomatoes (Solanum lycopersicum). Multispectral imageries with a spatial resolution of $1 \mathrm{~m}$ were successfully classified into healthy and diseased tomato when disease incidence reached stages 3 and above, but early disease detection below stage 3 was difficult due to its similar spectral response to that of the healthy vegetable (87). Most of the regression models developed for percent reflectance and percent defoliation in alfalfa caused by foliar pathogens were insignificant when disease levels were quite low two or more weeks prior to harvest, whereas nearly all models were significant on the day of harvest or 1 week earlier (52). Similar regression models $(28,29)$ found that $r^{2}$ values between percent reflectance and percent defoliation caused by foliar pathogens in alfalfa increased as the measurements were made closer to harvest or on the day of harvest. Even though slightly symptomatic plants were not included in our study as diseased, this omission was not considered problematic because the goal was to quantify severe symptoms of WSM that ultimately would result in reduced forage or grain yields. WSM is a progressive disease, and late infections, which result in greatly reduced symptom expression, cause significantly less damage to the crop $(60,82,83)$. Late infections that were not quantified in this study likely had no negative effect on crop yield. Furthermore, light infections that occurred early in the season and were not quantified in the earliest spring images likely were included in later images if they developed into severe, yield-limiting disease. The ability to easily and repeatedly monitor large areas during the growing season, at low cost, is perhaps the greatest advantage of this approach to disease quantification.

There are several possible reasons why some of the classifications in this study were incorrect. The reason for the false detection of two irrigated healthy wheat fields likely was due to the fact that these were furrow irrigated instead of the typical pivot irrigation. If there had been a greater number of furrow irrigated fields, it might have been important to differentiate between irrigation methods. Incorrect classification of three healthy dryland wheat fields as irrigated diseased fields perhaps was due to late but severe disease development. Alternatively, optimum growing conditions in the fall may have resulted in early, excessive vegetative growth, similar to an irrigated field, which was inordinately affected by late-season drought conditions. One possible solution to overcome these kinds of misclassifications is to evaluate NDVI or other spectral index values for separation of dryland and irrigated wheat as a baseline at the beginning of the growing season when disease is minimal. Images could be developed using this separation for masking out unwanted objects (e.g., irrigated wheat or dryland wheat) in images taken as the growing season progresses, and then, classifying images containing only dryland or irrigated wheat for disease detection. Among the four image classifications for WSM disease, spectral data acquired on 19 February 2008 had the lowest overall accuracy of $89.47 \%$ with a kappa value of 0.79 . This could be attributed to grazing impact and inadequate water availability for misclassified diseased wheat. Management practices vary greatly for irrigated and dryland wheat, and this affects vegetation regardless of disease presence. In addition, rapid disease development during the time between image collection and field verification also could account for incorrectly classified healthy wheat.

Quantification of midwinter wheat land area with Landsat TM remote sensing data indicated that land area identified as wheat was considerably lower than areas reported by the United States Department of Agriculture-National Agricultural Statistics Service (USDA-NASS) as being planted to wheat in the fall. In Castro County, total wheat land area determined from the 28 January 2006 Landsat TM image was 56,168 ha compared to 68,476 ha reported as planted. Similarly, wheat area determined from the 19 February 2008 Landsat TM image in Deaf Smith County was 64,189 ha compared to 80,532 ha reported by USDA-NASS as planted. These differences may be attributed to dryland wheat that failed either to germinate or grow due to drought, heavy grazing, and/or disease. All these factors, individually or combined, affected approximately $33 \%$ of the total planted wheat acreage that was carried to harvest The close agreement between USDA-NASS-reported irrigated wheat acreage $(29,947 \mathrm{ha})$ and that detected by image classification (31,036 ha) for Deaf Smith County in 2008 supports the accuracy of our estimations for irrigated wheat production. On 9 May 2008 , the total amount of wheat that remained for harvest $(21,062$ ha) was far less than the 32,577 ha $(17,725$ ha irrigated $+14,852$ ha dryland) reported by USDA-NASS. However, about a month earlier, on 7 April, harvestable wheat detected by Landsat TM image was 32,131 ha. Employees of the Farm Service Agency (personal communication) indicated that 3,075 ha of irrigated and 435 ha of dryland wheat were harvested for hay in 2008. It is most likely that the differences between wheat areas reported by USDA-NASS and that detected by TM image in May were lost due to WSM $(5,654$ ha dryland and 1,905 ha irrigated).

In summary, regional epidemics of WSM on commercial wheat crops occurred in the Texas Panhandle in 2006 and 2008. Landsat 5 TM imagery using MLC illustrated the geographical extent and distribution of areas with moderate to severe (extensive chlorotic streaking to complete leaf chlorosis and stunted plants) WSM. Detection was provided at a level that allowed accurate disease assessment, and was provided early enough to allow producers to make important management decisions, such as whether to continue irrigation, fertilization, and pest control. The current study indicates that high levels of accuracy are achievable for identifying WSM using Landsat 5 TM imagery. This process can therefore provide useful baseline input for real-time monitoring and mapping of WSM, its economics, and wheat inventory. Field verification of this disease remains labor-intensive, and weather conditions (i.e., cloud coverage) complicate obtaining images in a timely manner. Landsat 5 data also could be useful for quantifying past disease epidemics by obtaining and using archived images. The possibilities for identification of WSM within individual fields or farms 
needs to be investigated using remote sensing techniques, which could facilitate site-specific disease management at the individual field or farm scale.

\section{Acknowledgments}

We thank Casey Childers for his technical assistance in this project. We also acknowledge funding provided by the Great Plains Diagnostic Network and the Texas AgriLife Cropping Systems Research Initiative.

\section{Literature Cited}

1. Adams, M. L., Norvell, W. A., Philpot, W. D., and Peverly, J. H. 2000. Spectral detection of micronutrient deficiency in 'Bragg' soybean. Agron. J. 92:261-268.

2. Apan, A., Held, A., Phinn, S., and Markley, J. 2004. Detecting sugarcane 'orange rust' disease using EO-1 Hyperion hyperspectral imagery. Int. J. Remote Sens. 25:489-498.

3. Boschetti, L., Flasse, S. P., and Brivio, P. A. 2004. Analysis of the conflict between omission and commission in low spatial resolution dichotomic thematic products: The Pareto Boundary. Remote Sens. Environ. 91:280292.

4. Bravo, C., Moshou, D., West, J., McCartney, A., and Ramon, H. 2003. Early disease detection in wheat fields using spectral reflectance. Biosystems Eng. 84:137-145.

5. Broge, N. H., and Leblanc, E. 2000. Comparing prediction power and stability of broadband and hyperspectral vegetation indices for estimation of green leaf area index and canopy chlorophyll density. Remote Sens. Environ. 76:156-172.

6. Broge, N. H., and Mortensen, J. V. 2002. Deriving green crop area index and canopy chlorophyll density of winter wheat from spectral reflectance data. Remote Sens. Environ. 81:45-57.

7. Burrows, M., Franc, G., Rush, C., Blunt, T., Ito, D., Kinzer, K., Olson, J., O'Mara, J., Price, J., Tande, C., Ziems, A., and Stack, J. 2009. Occurrance of viruses in wheat in the Great Plains region, 2008. Plant Health Progress. Online publication. doi: 10.1094/PHP-2009-0706-01-RS

8. Carroll, M. W., Glaser, J. A., Hellmich, R. L., Hunt, T. E., Sappington, T. W., Calvin, D., Copenhaver, K., and Fridgen, J. 2008. Use of spectral vegetation indices derived from airborne hyperspectral imagery for detection of european corn borer infestation in Iowa corn plots. J. Econ. Entomol. 101:1614-1623.

9. Castillejo-González, I. L., López-Granados, F., García-Ferrer, A., PeñaBarragán, J. M., Jurado-Expósito, M., de la Orden, M. S., and GonzálezAudicana, M. 2009. Object- and pixel-based analysis for mapping crops and their agro-environmental associated measures using QuickBird imagery. Comput. Electron. Agric. 68:207-215.

10. Ceccato, P., Flasse, S., and Grégoire, J. M. 2002. Designing a spectral index to estimate vegetation water content from remote sensing data: Part 1: Theoretical approach. Remote Sens. Environ. 82:188-197.

11. Chen, B., Li, S., Wang, K., Wang, J., Wang, F., Xiao, C., Lai, J., and Wang, N. 2008. Spectrum characteristics of cotton canopy infected with Verticillium wilt and applications. Agric. Sci. China 7:561-569.

12. Congalton, R. G. 1991. A review of assessing the accuracy of classifications of remotely sensed data. Remote Sens. Environ. 37:35-46.

13. Congalton, R. G., and Green, K. 1999. Assessing the Accuracy of Remotely Sensed Data: Principles and Practices. Lewis Publishers, Boca Raton, FL.

14. Connin, R. V. 1956. The host range of the wheat curl mite, vector of wheat streak mosaic. J. Econ. Entomol. 49:1-4.

15. Divis, L. A., Graybosch, R. A., Peterson, C. J., Baenziger, P. S., Hein, G. L., Beecher, B. B., and Martin, T. J. 2006. Agronomic and quality effects in winter wheat of a gene conditioning resistance to Wheat streak mosaic virus. Euphytica 152:41-49.

16. Elliott, N., Mirik, M., Yang, Z., Dvorak, T., Rao, M., Michels, J., Walker, T., Catana, V., Phoofolo, M., Giles, K., and Royer, T. 2007. Airborne multispectral remote sensing of Russian wheat aphid injury to wheat. Southwest. Entomol. 32:213-219.

17. Elliott, N., Mirik, M., Yang, Z., Jones, D., Phoofolo, M., Catana, V., Giles, K., and Michels, J., Jr. 2009. Airborne remote sensing to detect greenbug stress to wheat. Southwest. Entomol. 34:205-211.

18. Fensholt, R., and Sandholt, I. 2003. Derivation of a shortwave infrared water stress index from MODIS near- and shortwave infrared data in a semiarid environment. Remote Sens. Environ. 87:111-121.

19. Franke, J., and Menz, G. 2007. Multi-temporal wheat disease detection by multi-spectral remote sensing. Precis. Agric. 8:161-172.

20. French, R., and Stenger, D. C. 2003. Evolution of Wheat streak mosaic virus: Dynamics of population growth within plants may explain limited variation. Annu. Rev. Phytopathol. 41:199-214.

21. Gamon, J. A., and Surfus, J. S. 1999. Assessing leaf pigment content and activity with a reflectometer. New Phytol. 143:105-117.

22. Gates, D. M. 1970. Physical and physiological properties of plants. Pages 224-252 in: Remote Sensing with Special Reference to Agriculture and Forestry. National Academy of Sciences, Washington, DC.

23. Genc, H., Genc, L., Turhan, H., Smith, S. E., and Nation, J. L. 2008. Vegetation indices as indicators of damage by the sunn pest (Hemiptera: Scutelleridae) to field grown wheat. Afr. J. Biotechnol. 7:173-180.
24. Gitelson, A. A., and Merzlyak, M. N. 1996. Signature analysis of leaf reflectance spectra: Algorithm development for remote sensing of chlorophyll. J. Plant Physiol. 148:494-500.

25. Gitelson, A. A., Merzlyak, M. N., and Chivkunova, O. B. 2001. Optical properties and nondestructive estimation of anthocyanin content in plant leaves. Photochem. Photobiol. 74:38-45.

26. Gitelson, A. A., Zur, Y., Chivkunova, O. B., and Merzlyak, M. N. 2002. Assessing carotenoid content in plant leaves with reflectance spectroscopy. Photochem. Photobiol. 75:272-281.

27. Guan, J., and Nutter, F. W., Jr. 2001. Factors that affect the quality and quantity of sunlight reflected from alfalfa canopies. Plant Dis. 85:865-874.

28. Guan, J., and Nutter, F. W., Jr. 2002. Relationships between defoliation, leaf area index, canopy reflectance, and forage yield in the alfalfa-leaf spot pathosystem. Comput. Electron. Agric. 37:97-112.

29. Guan, J., and Nutter, F. W., Jr. 2002. Relationships between percentage defoliation, dry weight, percentage reflectance, leaf-to-stem ratio, and green leaf area index in the alfalfa leaf spot pathosystem. Crop Sci. 42:1264-1273.

30. Harvey, T. L., Seifers, D. L., and Martin, T. J. 2001. Host range differences between two strains of wheat curl mites (Acari: Eriophyidae). J. Agric. Urban Entomol. 18:35-41.

31. Huang, W., Lamb, D. W., Song, X., Wang, Z., Niu, Z., Liu, L., and Wang, J. 2008. Estimating of winter wheat grain crude protein content from in situ reflectance and advance spaceborne thermal emission and reflection radiometer image. J. Appl. Remote Sens. 2:1-13.

32. Huang, W., Niu, Z., Zhang, Y., Liu, L., and Wang, J. 2007. Identification of yellow rust in wheat using in-situ spectral reflectance measurements and airborne hyperspectral imaging. Precis. Agric. 8:187-197.

33. Hunger, R. M., Sherwood, J. L., Evans, C. K., and Montana, J. R. 1992 Effects of planting date and inoculation date on severity of wheat streak mosaic in hard winter wheat cultivars. Plant Dis. 76:1056-1060.

34. Jones, D. 2004. Remote detection of wheat streak mosaic and nitrogen deficiency and their effects on hard red winter wheat. MS thesis. West Texas A\&M University, Canyon.

35. Jordan, C. F. 1969. Derivation of leaf-area index from quality of light on the forest floor. Ecology 50:663-666.

36. Kavzoglu, T., and Reis, S. 2008. Performance analysis of maximum likelihood and artificial neural network classifiers for training sets with mixed pixels. Gisci. Remote Sens. 45:330-342.

37. Lelong, C. C. D., Pinet, P. C., and Poilv, H. 1998. Hyperspectral imaging and stress mapping in agriculture: A case study on wheat in Beauce (France). Remote Sens. Environ. 66:179-191.

38. Li, H., Conner, R. L., Chen, Q., Graf, R. J., Lorache, A., Ahmad, F., and Kuzyk, A. D. 2004. Promising genetic resources for resistance to Wheat streak mosaic virus and the wheat curl mite in wheat-Thinopyrum partial amphiploids and their derivatives. Genet. Resour. Crop Ev. 51:827-835.

39. Liu, Z. Y., Shi, J. J., Zhang, L. W., and Huang, J. F. 2010. Discrimination of rice panicles by hyperspectral reflectance data based on principal component analysis and support vector classification. J. Zhejiang Univ.: Sci. B 11:71-78.

40. Liu, Z. Y., Wu, H. F., and Huang, J. F. 2010. Application of neural networks to discriminate fungal infection levels in rice panicles using hyperspectral reflectance and principal components analysis. Comput. Electron. Agric. 72:99-106.

41. Lu, D., and Weng, Q. 2007. A survey of image classification methods and techniques for improving classification performance. Int. J. Remote Sens. 28:823-870.

42. Malthus, T. J., and Madeira, A. C. 1993. High resolution spectroradiometry: Spectral reflectance of field bean leaves infected by Botrytis fabae. Remote Sens. Environ. 45:107-116.

43. Mirik, M., Michels, G. J., Jr., Kassymzhanova-Mirik, S., and Elliott, N. C. 2007. Reflectance characteristics of Russian wheat aphid (Hemiptera Aphididae) stress and abundance in winter wheat. Comput. Electron. Agric. 57:123-134.

44. Mirik, M., Michels, G. J., Jr., Kassymzhanova-Mirik, S., Elliott, N. C., and Bowling, R. 2006. Hyperspectral spectrometry as a means to differentiate uninfested and infested winter wheat by greenbug (Hemiptera: Aphididae). J. Econ. Entomol. 99:1682-1690.

45. Mirik, M., Michels, G. J., Jr., Kassymzhanova-Mirik, S., Elliott, N. C., Catana, V., Jones, D. B., and Bowling, R. 2006. Using digital image analysis and spectral reflectance data to quantify damage by greenbug (Hemiptera: Aphididae) in winter wheat. Comput. Electron. Agric. 51:8698.

46. Mirik, M., Michels, G. J., Mirik, S. K., Elliott, N. C., and Catana, V. 2006 Spectral sensing of aphid (Hemiptera: Aphididae) density using field spectrometry and radiometry. Turk. J. Agric. For. 30:421-428.

47. Mirik, M., Norland, J. E., Crabtree, R. L., and Biondini, M. E. 2005. Hyperspectral one-meter-resolution remote sensing in Yellowstone National Park, Wyoming: I. Forage nutritional values. Rangeland Ecol. Manage. 58:452-458.

48. Mirik, M., Steddom, K., and Michels, G. J., Jr. 2006. Estimating biophysical characteristics of musk thistle (Carduus nutans) with three remote sensing instruments. Rangeland Ecol. Manage. 59:44-54.

49. Nansen, C., Macedo, T., Swanson, R., and Weaver, D. K. 2009. Use of spatial structure analysis of hyperspectral data cubes for detection of insect- 
induced stress in wheat plants. Int. J. Remote Sens. 30:2447-2464.

50. Nilsson, H. E. 1991. Hand-held radiometry and IR thermography of plant diseases in field plot experiments. Int. J. Remote Sens. 12:545-557.

51. Nilsson, H. E., and Johnsson, L. 1996. Hand-held radiometry of barley infected by barley stripe disease in a field experiment. J. Plant Dis. Prot. 103:517-526.

52. Nutter, F. W., Jr., Guan, J., Gotlieb, A. R., Rhodes, L. H., Grau, C. R., and Sulc, R. M. 2002. Quantifying alfalfa yield losses caused by foliar diseases in Iowa, Ohio, Wisconsin, and Vermont. Plant Dis. 86:269-277.

53. Nutter, F. W., Jr., and Littrell, R. H. 1996. Relationships between defoliation, canopy reflectance and pod yield in the peanut-late leafspot pathosystem. Crop Prot. 15:135-142.

54. Nutter, F. W., Jr., Tylka, G. L., Guan, J., Moreira, A. J. D., Marett, C. C., Rosburg, T. R., Basart, J. P., and Chong, C. S. 2002. Use of remote sensing to detect soybean cyst nematode-induced plant stress. J. Nematol. 34:222231.

55. Pal, M., and Mather, P. M. 2004. Assessment of the effectiveness of support vector machines for hyperspectral data. Future Gener. Comp. Sy. 20:12151225.

56. Peñuelas, J., and Filella, L. 1998. Technical focus: Visible and near-infrared reflectance techniques for diagnosing plant physiological status. Trends Plant Sci. 3:151-156.

57. Pethybridge, S. J., Hay, F., Esker, P., Groom, T., Wilson, C., and Nutter, F. W., Jr. 2008. Visual and radiometric assessments for yield losses caused by ray blight in pyrethrum. Crop Sci. 48:343-352.

58. Pethybridge, S. J., Hay, F., Esker, P., Wilson, C., and Nutter, F. W., Jr. 2007. Use of a multispectral radiometer for noninvasive assessments of foliar disease caused by ray blight in pyrethrum. Plant Dis. 91:1397-1406.

59. Price, J. A., Smith, J., Simmons, A., Fellers, J., and Rush, C. M. 2010. Multiplex real-time RT-PCR for detection of Wheat streak mosaic virus and Tritcum mosaic virus. J. Virol. Methods 165:198-201.

60. Price, J. A., Workneh, F., Evett, S. R., Jones, D. C., Arthur, J., and Rush, C. M. 2010. Effects of Wheat streak mosaic virus on root development and water-use efficiency of hard red winter wheat. Plant Dis. 94:766-770.

61. Qin, Z., and Zhang, M. 2005. Detection of rice sheath blight for in-season disease management using multispectral remote sensing. Int. J. Appl. Earth Observ. Geoinf. 7:115-128.

62. Raikes, C., and Burpee, L. L. 1998. Use of multispectral radiometry for assessment of Rhizoctonia blight in creeping bentgrass. Phytopathology 88:446-449.

63. Reisig, D., and Godfrey, L. 2007. Spectral response of cotton aphid(Homoptera: Aphididae) and spider mite- (Acari: Tetranychidae) infested cotton: Controlled studies. Environ. Entomol. 36:1466-1474.

64. Richards, J. A., and Jia, X. 2006. Remote Sensing Digital Image Analysis: An Introduction. Springer-Verlag, Berlin.

65. Richardson, A. D., Aikens, M., Berlyn, G. P., and Marshall, P. 2004. Drought stress and paper birch (Betula papyrifera) seedlings: Effects of an organic biostimulant on plant health and stress tolerance, and detection of stress effects with instrument-based, noninvasive methods. J. Arboricult. 30:52-61.

66. Riedell, W. E., and Blackmer, T. M. 1999. Leaf reflectance spectra of cereal aphid-damaged wheat. Crop Sci. 39:1835-1840.

67. Rodriguez, D., Fitzgerald, G. J., Belford, R., and Christensen, L. K. 2006. Detection of nitrogen deficiency in wheat from spectral reflectance indices and basic crop eco-physiological concepts. Aust. J. Agric. Res. 57:781-789.
68. Rodríguez-Pérez, J. R., Riaño, D., Carlisle, E., Ustin, S., and Smart, D. R. 2007. Evaluation of hyperspectral reflectance indexes to detect grapevine water status in vineyards. Am. J. Enol. Viticult. 58:302-317.

69. Rouse, J. W., Naas, R. H., Schell, J. A., and Deering, D. W. 1973. Monitoring vegetation systems in the Great Plains with ERTS. Pages 309317. NASA, Washington, DC

70. Sánchez-Sánchez, H., Henry, M., Cárdenas-Soriano, E., and AlvizoVillasana, H. F. 2001. Identification of Wheat streak mosaic virus and its vector Aceria tosichella in Mexico. Plant Dis. 85:13-17.

71. Serrano, L., Peñuelas, J., and Ustin, S. L. 2002. Remote sensing of nitrogen and lignin in Mediterranean vegetation from AVIRIS data: Decomposing biochemical from structural signals. Remote Sens. Environ. 81:355-364.

72. Short, N. M. 2009. Remote sensing tutorial. NASA. Online publication.

73. Sivamani, E., Brey, C. W., Talbert, L. E., Young, M. A., Dyer, W. E., Kaniewski, W. K., and Qu, R. 2002. Resistance to Wheat streak mosaic virus in transgenic wheat engineered with the viral coat protein gene. Transgenic Res. 11:31-41.

74. Slykuis, J. T. 1955. Aceria tulipae Keifer (Acarina: Eriophydae) in relation to wheat streak mosaic. Phytopathology 45:116-128.

75. Steddom, K., Bredehoeft, M. W., Khan, M., and Rush, C. M. 2005. Comparison of visual and multispectral radiometric disease evaluations of Cercospora leaf spot of sugar beet. Plant Dis. 89:153-158.

76. Steddom, K., Heidel, G., Jones, D., and Rush, C. M. 2003. Remote detection of rhizomania in sugar beets. Phytopathology 93:720-726.

77. Stenger, D. C., and French, R. 2009. Wheat streak mosaic virus genotypes introduced to Argentina are closely related to isolates from the American Pacific Northwest and Australia. Arch. Virol. 154:331-336.

78. Swain, P. H., and Davis, S. M. 1978. Remote Sensing: The Quantitative Approach. McGraw-Hill, New York.

79. Tucker, C. J. 1979. Red and photographic infrared linear combinations for monitoring vegetation. Remote Sens. Environ. 8:127-150.

80. Velandia, M., Rejesus, R. M., Jones, D. C., Price, J. A., Workneh, F., and Rush, C. M. 2010. Economic impact of Wheat streak mosaic virus in the Texas High Plains. Crop Prot. 29:699-703.

81. West, J. S., Bravo, C., Oberti, D. L., Moshou, D., and McCartney, H. A 2003. The potential of optical canopy measurement for targeted control of field crop diseases. Annu. Rev. Phytopathol. 41:593-614.

82. Workneh, F., Jones, D. C., and Rush, C. M. 2009. Quantifying wheat yield across the field as a function of streak mosaic intensity: A state space approach. Phytopathology 99:432-440.

83. Workneh, F., Price, J. A., Jones, D. C., and Rush, C. M. 2010. Wheat streak mosaic: A classic case of plant disease impact on soil water content and crop water-use efficiency. Plant Dis. 94:771-774.

84. Yang, C., Everitt, J. H., and Johnson, H. B. 2009. Applying image transformation and classification techniques to airborne hyperspectral imagery for mapping Ashe juniper infestations. Int. J. Remote Sens 30:2741-2758.

85. Yang, Z., Rao, M. N., Elliott, N. C., Kindler, S. D., and Popham, T. W. 2005. Using ground-based multispectral radiometry to detect stress in wheat caused by greenbug (Homoptera: Aphididae) infestation. Comput. Electron. Agric. 47:121-135.

86. Yang, Z., Rao, M. N., Elliott, N. C., Kindler, S. D., and Popham, T. W. 2009. Differentiating stress induced by greenbugs and Russian wheat aphids in wheat using remote sensing. Comput. Electron. Agric. 67:64-70.

87. Zhang, M., Qin, Z., and Liu, X. 2005. Remote sensed spectral imagery to detect late blight in field tomatoes. Precis. Agric. 6:489-508. 